\title{
Heating Characteristics of Film prepared with Polymer Composites containing Graphite.
}

\author{
Seojin $\mathrm{Kim}^{1}$, Weontae $\mathrm{Oh}^{1 *}$, Jong-Seong Bae ${ }^{2}$, Jeong Hyun Yeum ${ }^{3}$, \\ Jaehyung Park ${ }^{1}$, Choonghyun Sung ${ }^{1}$, Jeongsoo Kim ${ }^{4}$
}

1 Division of Advanced Materials Engineering, Dong-Eui University, Busan, KOREA,47340

2 Busan Center, Korea Basic Science Institute, Busan 46742 KOREA

3 Department of Bio-Fibers and Materials Science, Kyungpook National University, Daegu 41566 KOREA

$4 \quad$ Biomedical R\&D Center, Pusan National University Hospital, Busan 46241 KOREA

*Correspondence: wtoh2005@deu.ac.kr; Tel.: +82-51-890-1721; http://orcid.org/0000-0003-19589604

\begin{abstract}
Heating films were prepared by using poly(methyl methacrylate) and polybutadiene composites containing graphite. The heating film was prepared by casting the as-made polymer composite on PET film. Copper electrodes were attached to both ends of the as-prepared film, and the heating characteristics of the film was analyzed while applying DC voltage. The electrical conductivity and the heating temperature of the heating films depended on the size, the structure, the content and the dispersion characteristics of the graphite in the composite. The electrical resistance of the heating film was controlled to adjust the heating temperature of the film. The relationship between the physical/chemical structure and the heating characteristics of the composite film was studied by measuring the heating temperature as functions of film thickness and resistance by using
\end{abstract}


an infrared thermal imaging camera. The lower the film resistance, the higher the heating temperature of the film. The surface temperature was uniform throughout the film.

Keywords: energy efficiency; flexibility; heating film; graphite; composite material

\section{Introduction}

Heating film is a heating element that generates thermal energy from the film surface, based on the principle of Joule heating (also known as Ohmic heating) [1]. When copper electrodes are attached to both ends of a heating film and a rated voltage is applied on the film, thermal energy is generated over the entire surface of the film. Generally, a heating film radiates thermal energy converted from electric energy. The temperature of a heating film can be easily controlled and the use of the heating film does not pollute the air, so it has advantages in terms of hygiene and noise [2,3]. For this reason, the heating films are widely used for home heating system in Europe, and the application areas have been expanded to the industrial fields of dryers, healthcare aids, and building materials as well as housing $[4,5]$.

In the heating film containing carbon materials for the use as a conductive filler, the electrical resistances caused by the interconnection of a myriad of carbon particles generate the thermal energy when current is applied. The heating films prepared with carbon composites exhibit excellent electrical/thermal conductivity and the weatherability, and the research on the carbon-based heating technology has been actively conducted in the academic and industrial fields [6,7].

The properties of a heating film are dependent on the kind of polymeric binders and conductive fillers used. As electric current is applied in the heating film, thermal energy is generated on the film surface, in which lots of contact resistances are formed between the conductive particles dispersed in the polymer matrix of the heating film. The thermal energy generated from the heating film is 
considerably influenced by the polymer binder, the type and the structure of thermal conductive materials used in the film, and the morphology of the as-prepared film [8-12].

Poly(methyl methacrylate) (PMMA) has good weatherability and durability and is suitable for outdoor use, and all kinds of processes such as heating, machining, printing are easily applied to this polymer. Crystalline PMMA is good for heat transfer and is stable at high temperature when used as a binder of a heating film. Therefore, it is suitable for external use $[13,14]$. Polybutadiene (PB) is a rubber material widely used for industrial purposes because it is low in density and good in weather resistance [15-17]. PB has low glass transition temperature $\left(T_{g},-20 \sim-80{ }^{\circ} \mathrm{C}\right)$, and it does not crack and is flexible at low temperatures [18]. When PB is used as a polymer binder, the heating films can be used for the pipe applications that require flexibility.

Carbon materials such as graphite, carbon nanotube, carbon fiber and graphene have high conductivity and excellent mechanical properties, and are applied in the fields where lightweight and high-performance composite materials are required. In general, thermally conductive ceramic materials are electrically insulated, but graphite is excellent in electrical conductivity because it has $\pi$-electrons due to its planar $s p^{2}$ carbon-carbon bond structure [19-22]. And graphite has high chemical stability and good workability, so it is easy for precision processing. Graphite is a suitable candidate as a conductive filler for the heating film because it is good in thermal resistance, thermal shock resistance and thermal/electrical conductivity [23,24].

In this study, PMMA and PB composite films containing graphite were prepared and their heating characteristics was analyzed. The temperature elevation of the film surface due to heat generation was analyzed by using an infrared thermal imaging camera while adjusting the graphite amount of composite films, film thickness and applied voltage.

\section{Materials and Methods}

\subsection{Preparation of composites and heating films}


To use as binders for the preparation of polymer composites, poly(methyl methacrylate) (PMMA, $\left.\overline{M_{n}}=\sim 103,000\right)$ and polybutadiene $\left(\mathrm{PB}, \overline{M_{n}}=\sim 3,000\right)$ were purchased from LG MMA and Aldrich, respectively. These polymer binders were used without further purification. Toluene $(99.9+\%$, SK chemicals) was used for the solvent. Natural graphite was purchased from Graphite Týn (Micronised natural graphite, $<20 \mu \mathrm{m})$. PET film (thickness, $125 \mu \mathrm{m})$ was used as a substrate to which heating films were deposited, and a copper tape (width $20 \mathrm{~mm} \times$ thickness $50 \mu \mathrm{m}$ ) as the electrode of the heating film.

A composite using PMMA as a binder was prepared as follows; $18 \mathrm{~g}$ of PMMA was added to 40 $\mathrm{g}$ of toluene, and the mixture was stirred and sufficiently dissolved at $60{ }^{\circ} \mathrm{C}$. Then, a certain amount of graphite was added thereto at room temperature, and mixed at $500 \mathrm{rpm}$ for $2.5 \mathrm{~min}, 800 \mathrm{rpm}$ for $5.5 \mathrm{~min}$, and $1000 \mathrm{rpm}$ for $2 \mathrm{~min}$ using a Paste mixer (PM-500D, SUFLUX) to prepare the final PMMA composite. To prepare a composite using PB as a binder, a given amount of graphite was added to $20 \mathrm{~g}$ of PB solution in $20 \mathrm{~g}$ of toluene, and mixed at $500 \mathrm{rpm}$ for $2.5 \mathrm{~min}$ and $1000 \mathrm{rpm}$ for 2 min using a Paste mixer as above. The amount of graphite was adjusted to 30, 40, and $50 \mathrm{wt} . \%$ in the composite.

The schematics of a heating film was shown in Figure 1. A composite for preparing the heating film was deposited to a PET film to which a copper tape was attached, and coating was conducted to prepare the film of a certain thickness from 10 to $100 \mu \mathrm{m}$ using a bar coater. As-made heating film was dried at room temperature for more than $5 \mathrm{~h}$, and further dried at $60^{\circ} \mathrm{C}$ for overnight.

\subsection{Measurements}

The thermal stability of the polymer binder used in this study was analyzed by using TGA (TGA $\mathrm{N}-1000, \mathrm{SCINCO}$ ) under air flow of $40 \mathrm{cc} / \mathrm{min}$, where a heating rate was set to $5^{\circ} \mathrm{C} / \mathrm{min}$. The sheet resistance of the as-made heating film was measured by using a Loresta GP resistivity meter (MCPT610, Mitsubishi Chemical Co.) connected to a 4-pin probe. The heating temperature of the film was measured using the setup shown in Figure $1 \mathrm{~b}$. Both $\mathrm{Cu}$ electrodes of the heating film were connected to a power supply (GP-4303TP, EZ Digital) to generate thermal energy. A digital multimeter (MAS- 
830, MASTECH) was connected in series to the circuit on the film surface to measure the current during the heating temperature analysis. The heating temperature of the film was analyzed by using an infrared thermal imaging camera (FLIR-C3TM, FLIR Systems), based on the principle of emitting the light of the corresponding wavelength according to the temperature of the subject.

\section{Results and Discussion}

TGA was performed to study the thermal stability of poly(methyl methacrylate) (PMMA) and polybutadiene (PB) used as binders of the heating films prepared in this work as shown in Figure 2. The TGA measurement was conducted from room temperature to $800^{\circ} \mathrm{C}$ at a heating rate of $5^{\circ} \mathrm{C} / \mathrm{min}$ and in air flow of $40 \mathrm{cc} / \mathrm{min}$. Oxygen in the air atmosphere promotes the oxidative reaction of PMMA, resulting in pyrolysis of the side functional group $\left(-\mathrm{COOCH}_{3}\right)$ at $\sim 200^{\circ} \mathrm{C}$, followed by decomposition of the main chain at $\sim 350{ }^{\circ} \mathrm{C}$. PMMA was completely decomposed at $420^{\circ} \mathrm{C}$ or more, and PB at 600 ${ }^{\circ} \mathrm{C}$ or more, leaving no residue. PB had higher thermal stability than PMMA in the air. This result shows that both PMMA and PB can be used as base resins, considering that the general service condition of the heating film is $100{ }^{\circ} \mathrm{C}$ or less.

Electrical resistance is induced by a large number of the interfacial contacts formed between the graphite particles evenly dispersed in the polymer matrix. When voltage is applied to a heating film containing graphite, current flow generates the Joule heat, resulting in the temperature elevation of the film [1]. If the film resistance is too low, the film shows the same characteristics as the conductor. On the contrary, if the resistance is too high, it becomes non-conductive. It is difficult to convert electric energy into thermal energy in either case. A suitable level of resistance $\left(10^{1} \sim 10^{2} \Omega / \square\right)$ is required for use as a heating film. Figure 3 shows the effect of the film thickness and the amount of graphite on the sheet resistance of heating films. The 4-pin probe measurement was used to obtain the sheet resistance of the heating film prepared by using the bar coater [25-27]. Regardless of the type of base resin (PMMA or PB), the sheet resistance of the heating films including graphite decreased as the content of graphite increased. That is, the conductivity of the film was 
correspondingly improved. This indicates that PMMA composite with graphite (PMMAGr) film is relatively advantageous in the conduction characteristics than PB composite with graphite (PBGr) film, considering the stereoregularity and the polarity effect of the PMMA resin itself [28,29]. Eq. (1) demonstrates that the sheet resistance $\left(R_{S}\right)$ of the film is inversely proportional to the film thickness $(t)$. Therefore, it can be easily understood that the sheet resistance decreases as the film becomes thicker.

$$
R_{s}=1 /\left(\sigma_{s} t\right)
$$

Here, $\sigma_{s}$ is the in-plane conductivity. When $30 \mathrm{wt} . \%$ of graphite was added to both PMMAGr and PBGr, the sheet resistance of the film was $10^{2} \Omega / \square$ or more. As described above, it was difficult to obtain an adequate level of Joule heating characteristics in the film with high resistance.

Figure 4 shows the sheet resistance and the heating temperature measured on PMMAGr and PBGr films, which were fabricated in the dimension of $100 \mu \mathrm{m} \times 25 \mathrm{~cm} \times 14 \mathrm{~cm}$ and analyzed under DC $25 \mathrm{~V}$. As described above, increasing the amount of the graphite added to the film decreased the sheet resistance of the film (i.e., the conductivity of the film improved), and consequently increased the heating temperature. Under the same condition, PMMAGr film showed lower resistance and higher heating temperature than PBGr film. At the same content of graphite, the sheet resistance of the PBGr film was more than 10 times higher. The heating temperature was also higher in the PMMAGr film as the content of graphite increased: (PBGr) from $30{ }^{\circ} \mathrm{C}$ to $50{ }^{\circ} \mathrm{C}$ and (PMMAGr) from $32{ }^{\circ} \mathrm{C}$ to 135 ${ }^{\circ} \mathrm{C}$. When $30 \mathrm{wt} . \%$ of the graphite was added to both films of PMMAGr and PBGr, the heating temperature was as low as $30{ }^{\circ} \mathrm{C}$, but the heating temperature above $80^{\circ} \mathrm{C}$ were measured on the PMMAGr film containing $40 \mathrm{wt} . \%$ of graphite. The heating temperature was measured above $130^{\circ} \mathrm{C}$ on the PMMAGr containing $50 \mathrm{wt} . \%$ of graphite. In addition, the heating temperature of the films was stably maintained even under continuous use for over 7 days. The stable heating characteristics and the long-term reliability of the heating film are considerably affected by the thermal stability of 
the base resin used. As shown in the TGA analysis, PMMA and PB exhibit thermal stability at the temperature below $200{ }^{\circ} \mathrm{C}$. Therefore, the heating film might exhibit thermal stability below $200{ }^{\circ} \mathrm{C}$. The saturated temperature shown in the infrared thermal images was uniform within a deviation of 5 ${ }^{\circ} \mathrm{C}$ in the whole region, indicating that the graphite particles were evenly distributed in the base resin. Although the film can be fabricated with the graphite content of $50 \mathrm{wt} . \%$ or more, it is difficult to keep the mechanical properties of the film such as flexibility and toughness, so that it is not recommended as a composite for heating film.

According to the basic electricity theory, the Joule heating energy $(Q)$ is dependent on the voltage $(V)$, current $(I)$, resistance $(R)$ and time $(t)$ during which the current flows;

$$
\begin{gathered}
Q \propto V \times I \times t \\
\propto \frac{V^{2}}{R} \times t
\end{gathered}
$$

The current and the heating temperature measured while applying DC power to each PMMAGr film were summarized in Figure 5. As shown in eq. (2), the thermal energy $(Q)$ is proportional to $V, I$, and $t$ applied to the film at a constant resistance condition. In addition, the thermal energy is proportional to $V^{2}$ and inversely proportional to $R$ at a constant current condition. The results could be identified from the dotted circles in Figure 5b and 5c. In PMMAGr film including 50 wt.\% of graphite, the temperature of the film was easily adjusted over a wide range from $32{ }^{\circ} \mathrm{C}$ to $135{ }^{\circ} \mathrm{C}$ as the voltage and the current were changed. The heating temperature did not exceed $32{ }^{\circ} \mathrm{C}$ on the PMMAGr film including $30 \mathrm{wt} . \%$ of graphite even when the voltage increased to $24 \mathrm{~V}$. This is because the resistance of the film itself is too high (over $10^{2} \Omega / \square$ ) to allow current flow even when a voltage is applied.

\section{Conclusions}

Poly(methyl methacrylate) and polybutadiene composites with graphite were prepared, of which films have flexibility, durability and weatherability. As-prepared heating films exhibited stable 
heating performance under continuous use condition of $200{ }^{\circ} \mathrm{C}$ or less. The sheet resistance of the film decreased with the increase of the film thickness and the graphite content added to the film. When PMMA was used as a binder, its composite (PMMAGr) film exhibited relatively lower resistance and higher heating characteristics than the film (PBGr) using polybutadiene as a binder. The film requires the sheet resistance of less than $10^{2} \Omega / \square$ to ensure proper heating characteristics. Depending on the type of the base resin and the content of graphite used in the film, the heating temperature could be adjusted up to about $130{ }^{\circ} \mathrm{C}$. An electronic controller that can control the input current should be used for more precise temperature control.

Author Contributions: S.K. and W.O. designed the experiments; S.K., S.B. and J.K. conducted the experiments for preparation of samples and analyzed the data; J.Y., J.P. and C.S. contributed to interpret the data; J.P. and S.K. drafted the manuscript; J.Y. and W.O. contributed to revise the article.

Funding: This research was supported by Basic Science Research Program through the National Research Foundation of Korea (NRF) funded by the Ministry of Education (No. 2017R1D1A3B03034728).

\section{References}

[1] Kang, J.; Kim, H.; Kim, K. S.; Lee, S. K.; Bae, S.; Ahn, J. H.; Hong, B. H. High-performance graphene-based transparent flexible heaters. Nano letters. 2011, 11(12), 5154-5158. [CrossRef]

[2] Hei, T. K.; Raal, J. D. Heat capacity measurement by flow calorimetry: an exact analysis. AIChE journal. 2009, 55(1), 206-216. [CrossRef]

[3] Park, H. K.; Kim, S. M.; Lee, J. S.; Park, J. H.; Hong, Y. K.; Hong, C. H.; Kim, K. K. Flexible plane heater: Graphite and carbon nanotube hybrid nanocomposite. Synthetic Metals. 2015, 203, 127- 
[4] Jussila, K.; Valkama, A.; Remes, J.; Anttonen, H.; Peitso, A. The effect of cold protective clothing on comfort and perception of performance. International Journal of Occupational Safety and Ergonomics. 2010, 16(2), 185-197. [CrossRef]

[5] Pasut, W.; Zhang, H.; Arens, E.; Kaam, S.; Zhai, Y. Effect of a heated and cooled office chair on thermal comfort. HVAC\&R Research. 2013, 19(5), 574-583. [CrossRef]

[6] Al-Ghamdi, A. A.; El-Tantawy, F. New electromagnetic wave shielding effectiveness at microwave frequency of polyvinyl chloride reinforced graphite/copper nanoparticles. Composites Part A: Applied Science and Manufacturing. 2010, 41(11), 1693-1701. [CrossRef]

[7] Mehra, N.; Mu, L.; Zhu, J. Developing heat conduction pathways through short polymer chains in a hydrogen bonded polymer system. Composites Science and Technology. 2017, 148, 97-105 [CrossRef]

[8] Mehra, N.; Mu, L.; Ji, T.; Yang, X.; Kong, J.; Gu, J.; Zhu, J. Thermal transport in polymeric materials and across composite interfaces. Applied Materials Today. 2018, 12, 92-130. [CrossRef]

[9] Lin, Z.; Liu, Y.; Raghavan, S.; Moon, K. S.; Sitaraman, S. K.; Wong, C. P. Magnetic alignment of hexagonal boron nitride platelets in polymer matrix: toward high performance anisotropic polymer composites for electronic encapsulation. ACS applied materials \& interfaces. 2013, 5(15), 7633-7640. [CrossRef]

[10] Shen, H.; Guo, J.; Wang, H.; Zhao, N.; Xu, J. Bioinspired modification of h-BN for high thermal conductive composite films with aligned structure. ACS applied materials \& interfaces. 2015, 7(10), 5701-5708. [CrossRef]

[11] Lim, H. S.; Oh, J. W.; Kim, S. Y.; Yoo, M. J.; Park, S. D.; Lee, W. S. Anisotropically alignable magnetic boron nitride platelets decorated with iron oxide nanoparticles. Chemistry of Materials. 2013, 25(16), 3315-3319. [CrossRef] 
[12] Xu, X.; Pereira, L. F.; Wang, Y.; Wu, J.; Zhang, K.; Zhao, X.; Hong, B. H. Length-dependent thermal conductivity in suspended single-layer graphene. Nature communications. 2014, 5, 3689. [CrossRef]

[13] Miller, D. C.; Kurtz, S. R. Durability of Fresnel lenses: a review specific to the concentrating photovoltaic application. Solar Energy Materials and Solar Cells. 2011, 95(8), 2037-2068. [CrossRef] [14] Li, S.; Shen, J.; Tonelli, A. E. The influence of a contaminant in commercial PMMA: A purification method for its removal and its consequences. Polymer. 2018, 135, 355-361. [CrossRef]

[15] Li, K.; Zheng, J.; Zhi, J.; Zhang, K. Aging constitutive model of hydroxyl-terminated polybutadiene coating in solid rocket motor. Acta Astronautica, 2018. [CrossRef]

[16] Wang, J.; Vincent, J.; Quarles, C. A. Review of positron annihilation spectroscopy studies of rubber with carbon black filler. Nuclear Instruments and Methods in Physics Research Section B: Beam Interactions with Materials and Atoms. 2005, 241(1-4), 271-275. [CrossRef]

[17] Zhang, Y.; Mark, J. E.; Zhu, Y.; Ruoff, R. S.; Schaefer, D. W. Mechanical properties of polybutadiene reinforced with octadecylamine modified graphene oxide. Polymer. 2014, 55(21), 5389-5395. [CrossRef]

[18] https://www.polymersource.com/Resources/Thermal-analysis.pdf [CrossRef]

[19] Li, Y., Yang, T., Yu, T., Zheng, L., \& Liao, K. Synergistic effect of hybrid carbon nantubegraphene oxide as a nanofiller in enhancing the mechanical properties of PVA composites. Journal of Materials Chemistry. 2011, 21(29), 10844-10851. [CrossRef]

[20] Erol, M.; Celik, E. Graphite-flake carbon-black-reinforced polystyrene-matrix composite films deposited on glass-fiber woven fabrics as plane heaters. Mater. Technol. 2013, 47, 25-28. [CrossRef]

[21] An, J. E.; Jeong, Y. G. Structure and electric heating performance of graphene/epoxy composite films. European Polymer Journal. 2013, 49(6), 1322-1330. [CrossRef] 
[22] Potts, J. R.; Dreyer, D. R.; Bielawski, C. W.; Ruoff, R. S. Graphene-based polymer nanocomposites. Polymer. 2011, 52(1), 5-25. [CrossRef]

[23] Krause, B.; Boldt, R.; Häußler, L.; Pötschke, P. Ultralow percolation threshold in polyamide 6.6/MWCNT composites. Composites Science and Technology. 2015, 114, 119-125. [CrossRef]

[24] Zhang, W. B.; Zhang, Z. X.; Yang, J. H.; Huang, T.; Zhang, N.; Zheng, X. T.; Zhou, Z. W. Largely enhanced thermal conductivity of poly (vinylidene fluoride)/carbon nanotube composites achieved by adding graphene oxide. Carbon. 2015, 90, 242-254. [CrossRef]

[25] Smits, F. M. Measurement of sheet resistivities with the four-point probe. Bell System Technical Journal. 1958, 37(3), 711-718. [CrossRef]

[26] Li, J. C.; Wang, Y.; Ba, D. C. Characterization of semiconductor surface conductivity by using microscopic four-point probe technique. Physics Procedia. 2012, 32, 347-355. [CrossRef]

[27] Zhou, W.; Tang, Y.; Song, R.; Jiang, L.; Hui, K. S.; Hui, K. N.; Characterization of electrical conductivity of porous metal fiber sintered sheet using four-point probe method. Materials \& Design. 2012, 37, 161-165. [CrossRef]

[28] Kim, G. H.; Lee, D.; Shanker, A.; Shao, L.; Kwon, M. S.; Gidley, D.; Pipe, K. P. High thermal conductivity in amorphous polymer blends by engineered interchain interactions. Nature materials. 2015, 14(3), 295. [CrossRef]

[29] Wu, H.; Cai, K.; Zeng, H.; Zhao, W.; Xie, D.; Yue, Y.; Zhang, X. Time-domain transient fluorescence spectroscopy for thermal characterization of polymers. Applied Thermal Engineering. 2018, 138, 403-408. [CrossRef] 


\section{Figure Captions}

Figure 1. Schematics of (a) a heating film and (b) a circuit set for the heating measurement.

Figure 2. TGA thermograms of poly(methyl methacrylate) (PMMA) and polybutadiene (PB) used in this work. The measurement was conducted in air flow of $40 \mathrm{cc} / \mathrm{min}$. The heating rate was $5^{\circ} \mathrm{C} / \mathrm{min}$.

Figure 3. Sheet resistance of heating films, which were prepared with polymer/graphite composites; (a) PMMA/Graphite composite films : PMMAGr, and (b) PB/Graphite composite films : PBGr. The numbers enclosed in parentheses represent the amounts of graphite added to the composite films.

Figure 4. Sheet resistance and heating temperature as a function of the amount of graphite added to the heating film. Open symbols $(\circ$ and $\square)$ and filled symbols $(\bullet$ and $\mathbf{\square})$ represent the sheet resistance and the temperature measured in the film, respectively. The abbreviations in the figure represent as follows; (PBGr) polybutadiene/graphite composite film, and (PMMAGr) poly(methyl methacrylate)/graphite composite film. (R) and (T) after the abbreviations mean the sheet resistance and the temperature, respectively. Infrared thermal images were taken from the heating films while applying DC power of $24 \mathrm{~V}$; (a) PMMAGr and (b) PBGr films including $50 \mathrm{wt} \%$ of graphite. Thickness of both films was about $100 \mu \mathrm{m}$.

Figure 5. Heating temperature measured on the heating film under applying DC power; (a) PMMAGr-30, (b) PMMAGr-40, and (c) PMMAGr-50. The numbers of -30, -40, and -50 indicate the graphite amount (wt.\%) added to the composite films of $100 \mu \mathrm{m}$ thickness. 
(a)

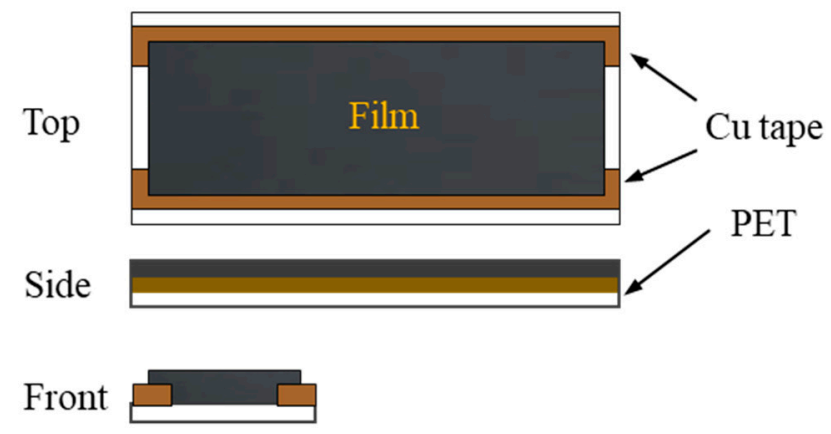

(b)

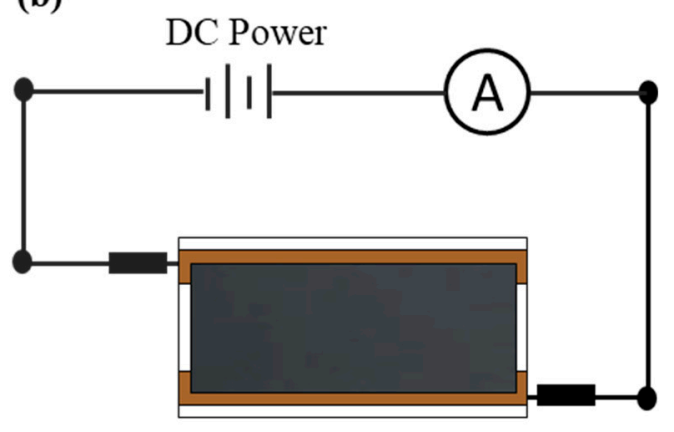

Figure 1 


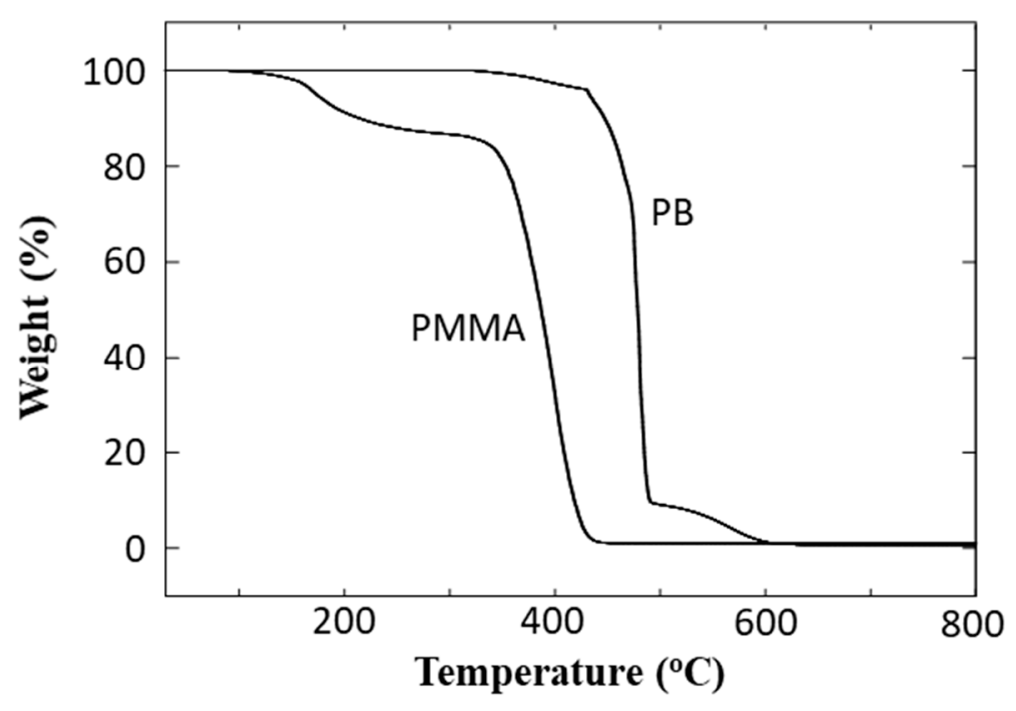

Figure 2 

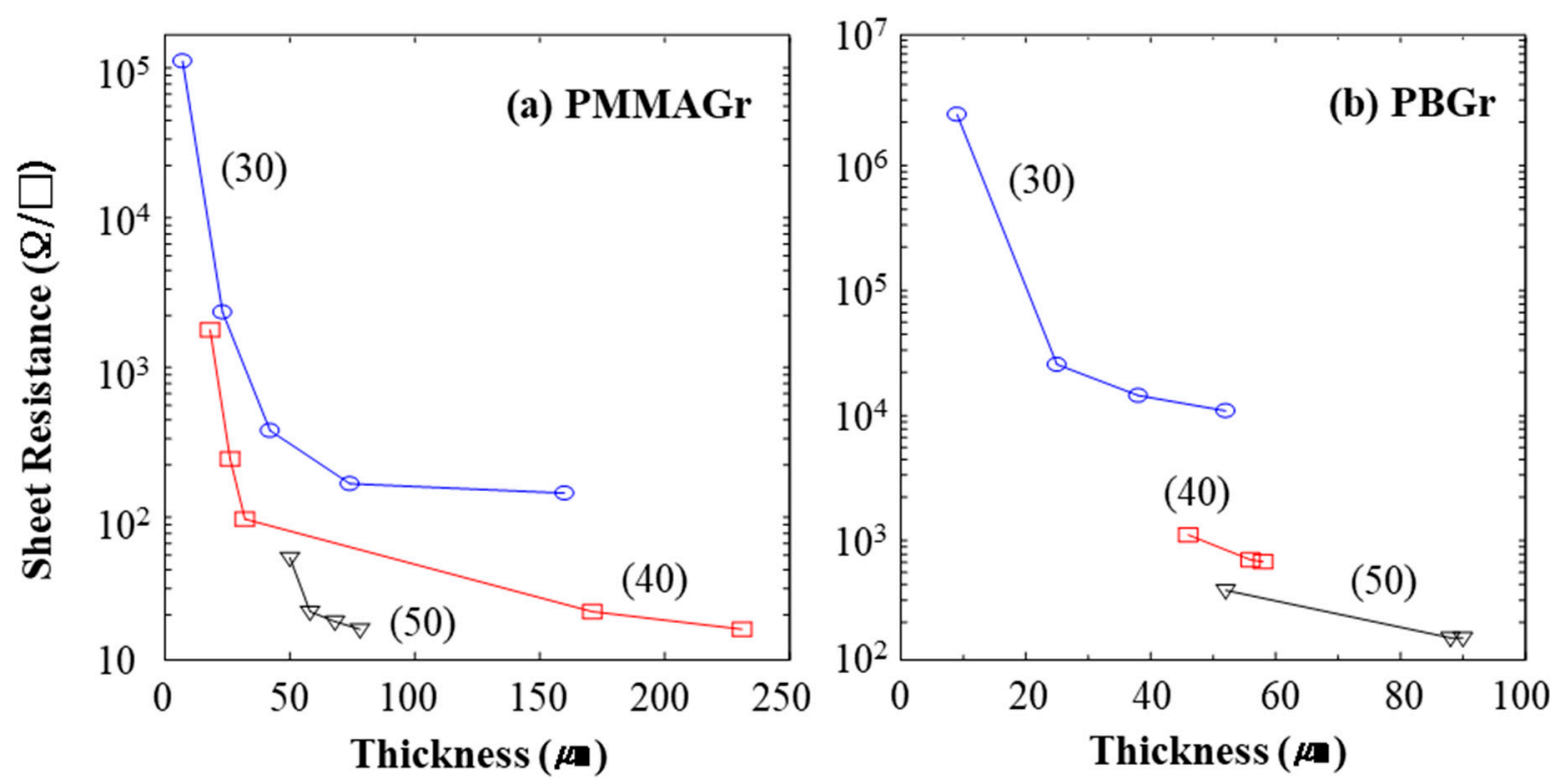

Figure 3 


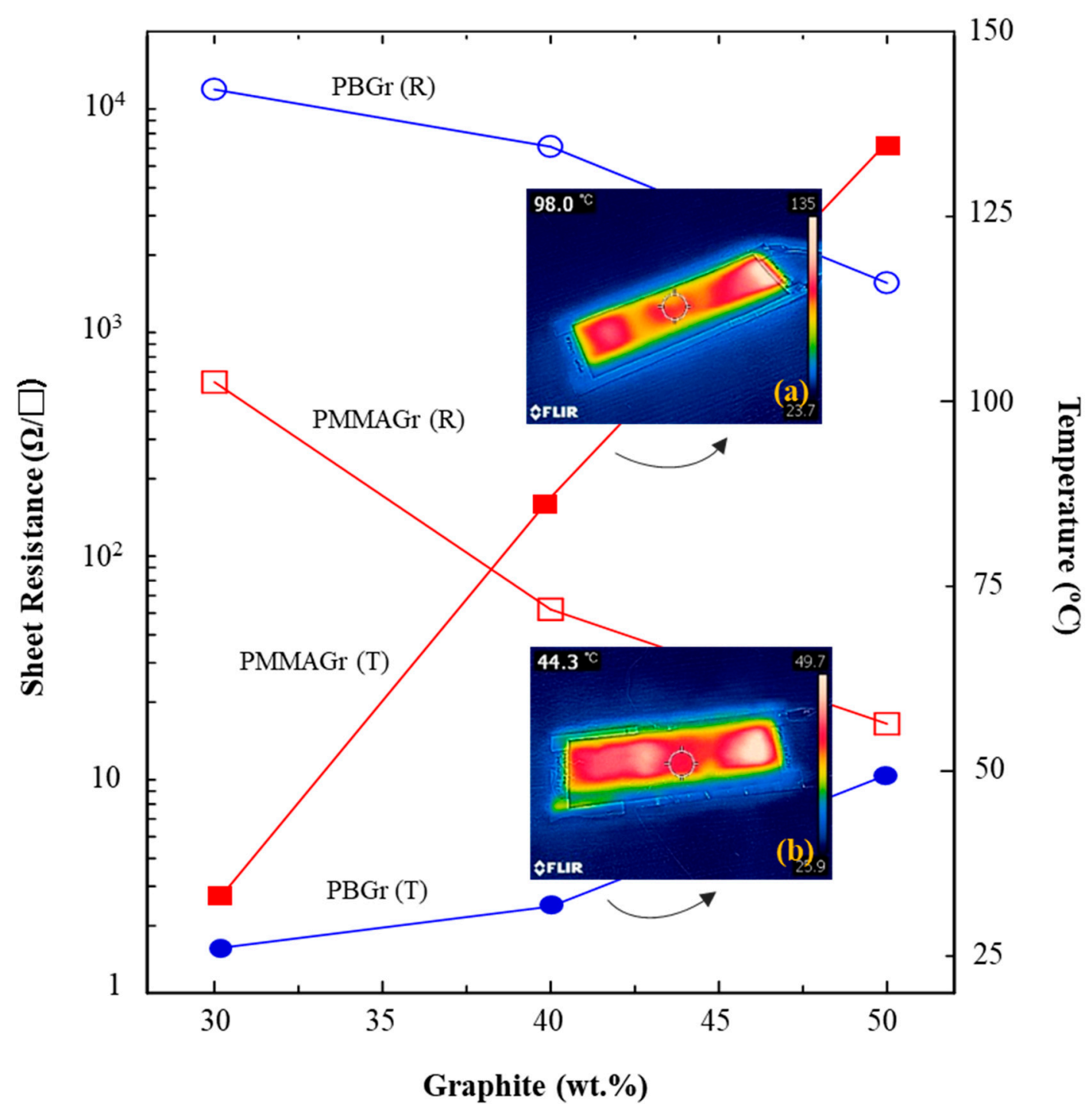

Figure 4 


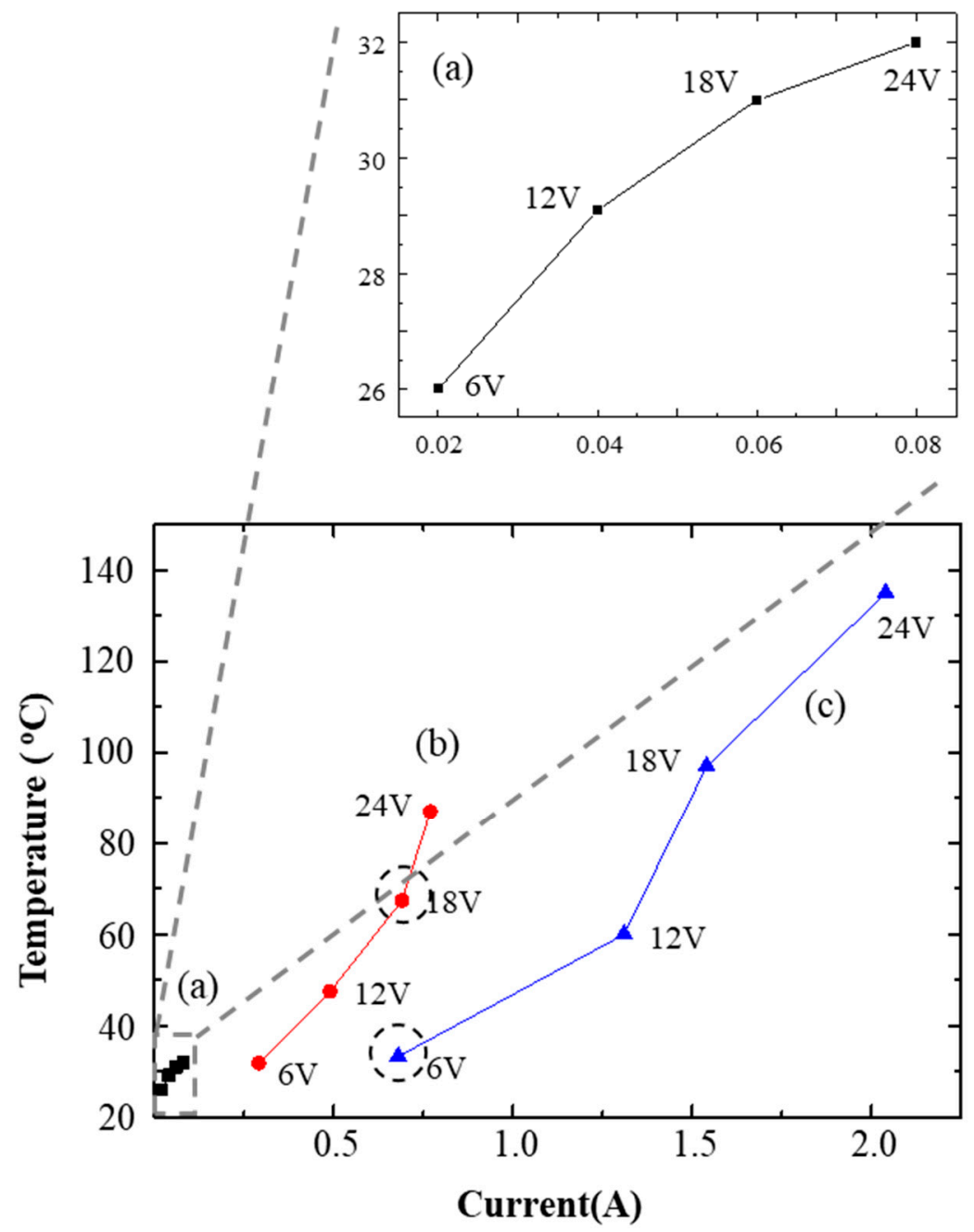

Figure 5. 